See Article page 1839.

\section{Commentary: History is prologue: If we fail to learn from our past, we are doomed to repeat it}

\author{
Amit Alam, MD, ${ }^{\mathrm{a}, \mathrm{b}, \mathrm{c}}$ Dan M. Meyer, MD, ${ }^{\mathrm{a}, \mathrm{c}, \mathrm{d}}$ and \\ Shelley A. Hall, MD ${ }^{\mathrm{a}, \mathrm{b}, \mathrm{c}}$
}

As the new heart allocation anniversary approaches this fall, the 1-year analysis performed by Estep and colleagues ${ }^{1}$ supports that the goals of the Organ Procurement and Transplantation Network (OPTN) were achieved: reduce waitlist mortality, reduce time to transplant, and broaden sharing of organs for the most urgent candidates. ${ }^{1}$ Additionally posttransplant 6-month survival did not differ. While an early victory for the transplant community, time will tell if the celebration continues.

History is educational. Nativi and colleagues ${ }^{2}$ compared the 2006 allocation policy with the former allocation system and found an increase in Status 1A transplants and ischemic times with decrease in Status 2 transplants and no effect on mortality, identical to Estep and colleagues ${ }^{1}$ Ten years later, OPTN reported congestion in status $1 \mathrm{~A}$ and one half of adult heart transplant recipients having a durable ventricular assist device (VAD) before transplant. ${ }^{3}$ VADs became embedded in our innate behavior.

The 2018 allocation was based on previous behaviors of a VAD-favorable environment because we knew patients could not survive months on temporary mechanical circulatory support (tMCS). Now patients with tMCS Status 2 are receiving nearly one half $(45.7 \%)$ of the heart transplants and skipping VAD. 1 How did we do in less than 2 years what took us a decade to do in the previous system: create a congested high status?

\footnotetext{
From the ${ }^{\mathrm{a} C e n t e r}$ for Advanced Heart and Lung Disease, Baylor Annette C. and Harold C. Simmons Transplant Institute, and ${ }^{\mathrm{d} C e n t e r}$ for Cardiothoracic Surgery, Baylor University Medical Center, Dallas; ${ }^{\mathrm{b}}$ Division of Cardiology, Department of Advanced Heart Failure, Mechanical Support, and Transplant, Baylor Heart and Vascular Hospital, Dallas; and ${ }^{\mathrm{c}}$ Texas A\&M University College of Medicine, Bryan, Tex.

Disclosures: Dr Hall reported consultant for Abiomed, Abbott, Medtronic, Syncardia, and Evaheart. All other authors reported no conflicts of interest.

The Journal policy requires editors and reviewers to disclose conflicts of interest and to decline handling or reviewing manuscripts for which they may have a conflict of interest. The editors and reviewers of this article have no conflicts of interest.

Received for publication Aug 27, 2020; revisions received Aug 27, 2020; accepted for publication Aug 28, 2020; available ahead of print Sept 3, 2020.

Address for reprints: Shelley A. Hall, MD, 3410 Worth St, Suite 250, Dallas, TX 75246 (E-mail: Shelley.Hall@bswhealth.org).

J Thorac Cardiovasc Surg 2021;161:1847-8

$0022-5223 / \$ 36.00$

Copyright (C) 2020 by The American Association for Thoracic Surgery

http://dx.doi.org/10.1016/j.jtcvs.2020.08.099
}

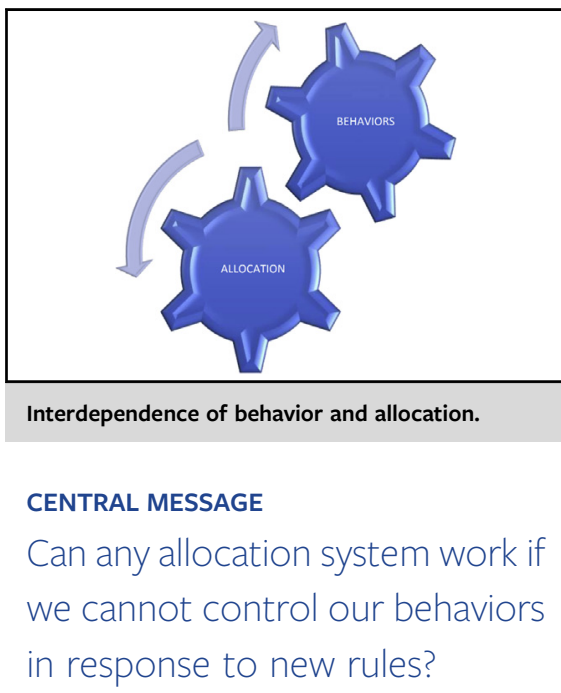

The surge in Status 2 is most notably driven by the balloon pump. ${ }^{1,4,5}$ While rising before 2018 , use of balloon pumps increased 3-fold since the new allocation was implemented. ${ }^{6}$ Furthermore, Status 2 faces another dilemma like 1A: increased exception requests. Between 2014 and 2015, 5340 of 5878 of all Status 1A/1B exception requests were for Status 1A. In comparison, $31 \%$ of all patients in Status 2 in the new allocation qualified by exception rather than established criteria. ${ }^{7}$

Compared with the other MCS bridging strategies, venoarterial extracorporeal membrane oxygenation was associated with the worst post-heart transplant survival. ${ }^{8}$ Yet, given recent French CRISTAL registry ${ }^{9}$ reporting favorable outcomes, can time, experience, growth of shock protocols, and early venting strategies improve our survival?

Additionally concerning, following the launch of the new allocation system, tMCS use in patients admitted with cardiogenic shock increased in US transplant centers but not in Canada or non-transplant centers in the United States. ${ }^{10}$ This begs the question-are we increasing tMCS use because of worsening patient illness or to transplant faster?

The Heart Committee of OPTN has recognized the behavior changes and created a guidance document to address this overcrowding. ${ }^{7}$ While Estep and colleagues ${ }^{1}$ imply early victories of the new allocation system to prioritize order of critical illness, the insights into our own behaviors and transplant decision patterns are disturbing. As a community, we need to acknowledge our innate competing goals of transplant center volumes, outcomes, and donor use. We are at a crossroads-are we choosing a future where only patients in the intensive care unit will obtain transplants, or do we return to a previous strategy when VAD was the interim step? We must recognize that, 
without moderating our behavior, we will break this young allocation system quickly.

\section{References}

1. Estep JD, Soltesz E, Cogswell R. The new heart transplant system: early observations and mechanical circulatory support considerations. J Thorac Cardiovasc Surg. 2021;161:1839-46.

2. Nativi JN, Kfoury AG, Myrick C, Peters M, Renlund D, Gilbert EM, et al. Effects of the 2006 U.S. thoracic organ allocation change: analysis of local impact on organ procurement and heart transplantation. J Heart Lung Transplant. 2010;29:235-9.

3. Colvin M, Smith JM, Hadley N, Skeans MA, Carrico R, Uccellini K, et al. OPTN/ SRTR 2016 annual data report: heart. Am J Transplant. 2018;18(suppl 1):291-362.

4. Huckaby LV, Seese LM, Mathier MA, Hickey GW, Kilic A. Intra-aortic balloon pump bridging to heart transplantation: impact of the 2018 allocation change. Circ Heart Fail. 2020;13:e06971.

5. OPTN Thoracic Transplantation Committee One-Year Monitoring of Heart Allocation Proposal to Modify the Heart Allocation System. Available at: https://optn. transplant.hrsa.gov/media/3701/data_report_thoracic_committee_heart_ subcommittee_20200227_rpt1_revised_508_compliant.pdf. Accessed July 1, 2020 .

6. Ouyang D, Gulati G, Ha R, Banerjee D. Incidence of temporary mechanical circulatory support before heart transplantation and impact on post-transplant outcomes. J Heart Lung Transplant. 2018;37:1060-6.

7. OPTN, Guidance and Policy Clarifications Addressing Adult Heart Allocation Policy Available at: https://optn.transplant.hrsa.gov/media/3931/guidance_poli cy_clarifications_address_adult_heart_allocation_policy.pdf. Accessed August 15, 2020.

8. Yin MY, Wever-Pinzon O, Mehra M, Selzman CH, Toll AE, Cherikh WS, et al. Post-transplant outcome in patients bridged to transplant with temporary mechanical circulatory support devices. J Heart Lung Transplant. 2019;38:858-69.

9. Jasseron C, Lebreton G, Cantrelle C, Legeai C, Leprince P, Flecher E, et al. Impact of heart transplantation on survival in patients on venoarterial extracorporeal membrane oxygenation at listing in France. Transplantation. 2016;100:1979-87.

10. Varshney AS, Berg DD, Katz JN, Baird-Zars VM, Erin A, Bohula EA, et al. Use of temporary mechanical circulatory support for management of cardiogenic shock before and after the united network for organ sharing donor heart allocation system changes. JAMA Cardiol. 2020;5:703-8.

\section{Commentary: Flying too close to}

\section{the sun}

\author{
Anh-Thu Le, MD, and Nahush A. Mokadam, MD
}

There is a well-known Greek myth in which the architect Daedalus crafts a pair of wax and feather wings to escape the clutches of the cruel King of Crete. Daedalus wishes to free his son Icarus first, and launches him away after warning his only child to not fly too high, as the sun's rays would melt the waxy wings. Alas, Icarus, young and eager, falls to his death after disregarding his father's admonition. ${ }^{1}$ While it is only an ancient story, it does still have relevance in the world of heart transplantation. Each year, more patients are listed for heart transplant whereas the number of donor hearts remains impertinently stagnant. ${ }^{2}$ Like the old inventor wanting to

From the Division of Cardiac Surgery, The Ohio State University Wexner Medical Center, Columbus, Ohio.

Disclosures: Dr Mokadam is a consultant for Medtronic, Abbott, SynCardia, and Carmat. Dr Le has reported no conflicts of interest.

The Journal policy requires editors and reviewers to disclose conflicts of interest and to decline handling or reviewing manuscripts for which they may have a conflict of interest. The editors and reviewers of this article have no conflicts of interest

Received for publication Sept 5, 2020; revisions received Sept 5, 2020; accepted for publication Sept 8, 2020; available ahead of print Sept 12, 2020.

Address for reprints: Nahush A. Mokadam, MD, Division of Cardiac Surgery, The Ohio State University, Columbus, OH 77030 (E-mail: Nahush.Mokadam@ osumc.edu).

J Thorac Cardiovasc Surg 2021;161:1848-9

$0022-5223 / \$ 36.00$

Copyright (c) 2020 by The American Association for Thoracic Surgery

http://dx.doi.org/10.1016/j.jtcvs.2020.09.028

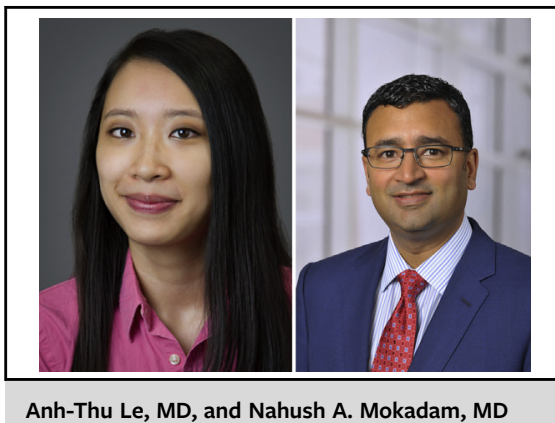

Anh-Thu Le, MD, and Nahush A. Mokadam, MD

CENTRAL MESSAGE

We must continue to optimize organ allocation with ongoing evaluation and modification of existing systems. Undoubtedly, this will cause some unanticipated outcomes that require vigilance.

save his son, we want to save our patients by transplanting as many donor hearts as we can to those who will benefit most.

In this issue of the Journal, Estep and colleagues ${ }^{3}$ discuss the outcomes on heart transplantation after the implementation of new adult heart allocation guidelines in October of 2018. There were changes for the better: for example, more patients received heart transplants after implementation of the guidelines, there were no changes to mortality over 180 days for patients who were listed, and the available donor network 